\title{
Beneficial effect of compound essential oil inhalation on central fatigue
}

\author{
Chenxia Han ${ }^{1}$, Feng Li ${ }^{1 *}$, Simin Tian², Yan Liu' ${ }^{1}$, Huai Xiao ${ }^{3}$, Xiumei $\mathrm{Wu}^{3}$, Weiyue Zhang ${ }^{1}$, Wei Zhang \\ and Meng Mao
}

\begin{abstract}
Backgrounds: Although the physical and mental enhancement effect of essential oils have been proved, the beneficial effect of essential oil in central fatigue remains unclear. In this study, we extracted essential oils from nine aromatic plants to make a compound essential oil, and detected the therapeutic effect of central fatigue by daily aerial diffusion.

Methods: Thirty-three rats were randomly and equally divided into control group, chronic sleep deprivation group, and compound essential oil inhalation group. Central fatigue was generated by chronic sleep deprivation.

Results: After 21-day various interferences, it is found that the sleep deprivation rats showed an evident decrease in physical endurance, negative emotion, and cognitive dysfunction compared with the control group, and the group that treated with the compound essential oil behaved significantly better than central fatigue group.

Conclusion: We concluded that this formula of essential oils could alleviate central fatigue on rats, and our study provides a new direction of application of aromatic therapy, which could be expanded to insomnia, depression and other healthy issue in the further research.
\end{abstract}

Keywords: Essential oil, Central fatigue, Traditional Chinese medicine

\section{Introduction}

A lot of clinical evidence has proved that aromatherapy could improve the brain function and alleviate fatigue [1]. The term 'aromatherapy' was coined by French chemist and perfumiér René Maurice Gattefossé in the 1920s [2]. Aromatherapy has been used as an effective method in complementary and alternative medicine, owning to its noninvasive operation, convenience in administration and fast results. Essential oils have been widely used as a treatment in body relaxing, mood enhancement, pain relief, anti-stress, improving cognitive efficiency, spirit well-being and many other psychological and physical conditions [3]. It can directly act on respiration system [4], circulation system [5], and central nervous system via skin and respiration tract. The basic mechanism of aromatherapy is the inhalation of volatile ingredients into respiration system, or absorption of

\footnotetext{
* Correspondence: lifeng_bucm0610@126.com

${ }^{1}$ Basic Medicine School, Beijing University of Chinese Medicine, Beijing,

People's Republic of China

Full list of author information is available at the end of the article
}

monomer ingredients into skin, finally take effect in certain organ. Some research argue that the connection between olfaction and the limbic system in the brain may be the main mechanism of aromatic therapy [1]. The scent receptors in the nose could send chemical messages via the olfactory nerve to the brain's limbic region, and then regulate the body function including blood pressure, breath, and emotion [6]. However, opinions based on this theory are controversial. Another research proposed that the augmentation of GABA could be the basic mechanism of lavender essential oil ameliorating convulsions in mice [7]. Studies focused on the molecular mechanism during aromatic functioning with significance remains absent.

Central fatigue was first reported in 1904 by A. Mosso [8]. It represents a failure to complete mental and physical tasks in the absence of demonstrable cognitive failure or motor weakness [9], and could be resulted from the dysfunction of central nerves system [10]. Clinical manifestation related to central fatigue reported in current literatures mainly including fatigue sensation,

(c) The Author(s). 2018 Open Access This article is distributed under the terms of the Creative Commons Attribution 4.0 International License (http://creativecommons.org/licenses/by/4.0/), which permits unrestricted use, distribution, and reproduction in any medium, provided you give appropriate credit to the original author(s) and the source, provide a link to the Creative Commons license, and indicate if changes were made. The Creative Commons Public Domain Dedication waiver (http://creativecommons.org/publicdomain/zero/1.0/) applies to the data made available in this article, unless otherwise stated. 
weakness of physical function, low efficiency during mental task, and negative emotions including anxiety, depression [11]. It is a complex state which could be induced by massive physical and/or mental tasks [12]. Several neurotransmitters such as 5-HT and DA have been studied to be related to central fatigue [13, 14]. Although relax therapy [15] and sufficient oxygen [16] could improve the situation, an effective and suitable medical intervention for central fatigue remains absent.

The aromatherapy plays an important role in fatigue treatments due to the positive physical and mental effects [17]. It is known that relax therapy could alleviate central fatigue cause it could relax the intensive state of central nervous system and muscle [15]. And it could improve sleep and depression, and the whole well-being in cancer patients [18]. As an important role in relaxing treating, essential oils inhalation has been proved to be effective in mental exhaustion and burnout [19], and the prevention and treatment of stress and fatigue as well [20]. In addition, accumulated evidence of clinical trials has indicated that the intractable fatigue and other conditions caused by cancer [21, 22] and radiotherapy [23, 24], could be relieved by essential oil. Although some clinical evidence indicated the effectiveness on burn out and mental fatigue, few research has investigated the effect of this treatment on central fatigue.

Sleep deprivation could generate central fatigue on rats [25]. As we introduced above, essential oil inhalation could improve fatigue, and it could improve sleep issues as well [26], due to its central function enhancement and spirit well-being effects. Thus, in this research, we employed chronic sleep deprivation to generate central fatigue on rats [27], and used a compound essential oil made from selected natural plants, which have been proved to exhibited evident effect on mental disorders $[28,29]$, cognitive tasks [30], negative emotions [31]. We reported a pharmacodynamics study of compound essential oil in central fatigue, by analyzing central fatigue related measurement such as physical endurance, emotion, decision-making capacity, locomotor activity through behavioral tests, to evaluate the beneficial properties of this compound essential oil.

\section{Materials and methods \\ Animals}

Male (weighing $200 \pm 10 \mathrm{~g}$ ) Wistar rats were purchased from Beijing Vital River Laboratory Animal Technology Limited Company (Beijing, China). The animals were maintained in a room with a constant temperature of 23 $\pm 1{ }^{\circ} \mathrm{C}$; a relative humidity of $30-40 \%$; light for $12 \mathrm{~h}$ from 06:00 to 18:00; and ad libitum food and purified water. Thirty three rats were randomly divided into three groups as follows: control group $(\mathrm{CON}$, rats were fed routinely for 21 days, $n=11$ ), chronic sleep deprivation group (CSD, rats were promoted by chronic sleep deprived for 21 days, $n=11$ ), compound essential oil group (CEO, rats were promoted with chronic sleep deprived for 21 days with compound essential oil inhalation every day, $n=11$ ).

The rats were anaesthetised with an intraperitoneal injection of $10 \%$ pentobarbital sodium $(4 \mathrm{ml} / \mathrm{kg})$ and subsequently sacrificed by rapid decapitation.

The experiments were approved by the Institutional Animal Ethics Committee of Beijing University of Chinese Medicine. All animals were maintained in accordance with the guidelines outlined by the Chinese legislation on the ethical use and care of laboratory animals. All efforts were made to minimize both animal suffering and the number of animals used to produce reliable data.

\section{Compound essential oil preparation and administration}

The compound essential oil was a mixture formula including nine natural plants essential oils. It consist of Santalum album, Citrus aurantium, Citrus limonum, Styrax benzoin, Citrus paradisi, Mentha piperata, Acori tatarinowii rhizoma, Rhodiolae crenulatae radix et rhizoma, and Camellia sinensis (linn.)o. ktze.

Pure essential oils of Santalum album, Citrus aurantium, Citrus limonum, Styrax benzoin, Citrus paradisi, Mentha piperata, were purchased from Beijing Piaowang Science Technology Co, Ltd.(China). Essential oils of Acori tatarinowii rhizoma, Rhodiolae crenulatae radix et rhizoma, and Camellia sinensis (linn.)o. ktze were prepared follow the method in Pharmacopoeia of People's Republic of China [32] respectively. In detail, the crude drug were purchased from Beijing Tongrentang Drug Strore (China), $\operatorname{drug}(100 \mathrm{~g}$ per drug) was boiled in 1000 $\mathrm{ml}$ distilled water for $6-7 \mathrm{~h}$ in a heating laboratory flask, the essential oil was collected using a condenser pipe during the boiling. Finally, the three collected essential oil of Acori tatarinowii rhizoma, Rhodiolae crenulatae radix et rhizoma, and Camellia sinensis (linn.)o. ktze was mixed with purchased single essential oils, together to make a compound essential oil with a specific mixing proportion. (The mixing ratio of Santalum album, Citrus aurantium, Citrus limonum, Styrax benzoin, Citrus paradisi, Mentha piperata, Acori tatarinowii rhizoma, Rhodiolae crenulatae radix et rhizoma, and Camellia sinensis (linn.)o. ktze was 8:4:4:5:1:6:0.2:0.2:0.2).

Rats in CEO group were taken to a separate room whose environment was same as the original experiment room for inhalation of compound essential oil for 45 min every training day on 9:00 am. Essential oils was inhaled by adding $100 \mu \mathrm{l}$ to $300 \mathrm{ml}$ water in an aroma humidifier which spread the aroma throughout the room. After inhalation, they were taken back to the experiment room [33]. 
Gas chromatography-mass spectrometry analysis

GC-MS was performed with gas chromatography instrument (Agilent Technologies 7890A) coupled to a mass spectrometer (Agilent Technologies 5975C). Compounds were separated on aHP-5 MS capillary column (Agilent, $30 \mathrm{~m} \times 0.25 \mathrm{~mm}, 0.25 \mu \mathrm{m}$ ).

The column temperature was maintained for $1 \mathrm{~min}$ at $40{ }^{\circ} \mathrm{C}$ during desorption, then ramped to $280^{\circ} \mathrm{C}$ at $5^{\circ} \mathrm{C} /$ $\mathrm{min}$, and kept for $3 \mathrm{~min}$ at $280^{\circ} \mathrm{C}$. Splitless injection was conducted and helium was used as carrier gas with the flow-rate of $1.0 \mathrm{~mL} / \mathrm{min}$. The spectrometer was operated in electron-impact (EI) mode with the scan range 50-550 $\mathrm{m} / \mathrm{z}$, the ionization energy $70 \mathrm{eV}$, and the scan rate $0.2 \mathrm{~s}$ per scan. The ionization source temperature was $230^{\circ} \mathrm{C}$.

The volatile components were identified by mass spectral comparison with the spectra of reference compounds in National Institute of Standards and Technology (NIST) mass spectral library.

\section{Chronic sleep deprivation}

The chronic sleep deprivation was generated by modified multiple platform method [34]. This method has been reported to interfere with total sleep, mainly rapid eye moved sleep [35]. Rats in CSD group were deprived sleeping for $14 \mathrm{~h}$ per day from 18:00 to 8:00, last for 21 days, according to our previous research [36]. The equipment for modified multiple platform method was made with plastic, and there are 15 platforms placed on the bottom of the tank $(110 \times 60 \times 40 \mathrm{~cm})$; they were surrounded by water at a temperature of $20-22{ }^{\circ} \mathrm{C}$ at a depth of $1.0 \mathrm{~cm}$ below the platform surface; iron cages and bottles were filled with food and water, respectively, on the top of the tank. Thus, the rats could move around inside the tank by jumping from one platform to another. When rats fall asleep, they will fall into the water and wake up.

\section{Weight-loaded forced swimming (WFS)}

WFT was promoted after 21-day training followed the described method [37]. Rats were forced to swim individually in a plastic pool which was filled with water at a temperature of $20-22^{\circ} \mathrm{C}$ and a depth of $60 \mathrm{~cm}$. A tin wire ( $10 \%$ of body weight) was loaded on the tail root of each rat. The endurance capacity was recorded as the time rat began to swim till exhausted. The rats were assessed to be exhausted when they failed to rise to the surface of water to breathe within a10 s period. At swimming session, rats were taken out from the water and dried with a towel, and put back in their home cages. Water was drained after each rat swimming.

\section{Open field test (OFT)}

OFT was promoted after 21-day training. This test provides a novel environment in which to measure animal locomotion, exploration, and anxiety [38]. The open field arena $(100 \times 100 \times 40 \mathrm{~cm})$ is constructed of acrylic, with gray walls and a black floor, which is divided into 25 equally sized areas, as previously described [39]. The time spent in central area, number of crossing squares, total distance travelled, maximum continuous distance travelled, the mean velocity, time and frequency of vertical activity, time and frequency of grooming behavior and the number of defecations were measured. Each rat was tested for $5 \mathrm{~min}$. Measures were assessed using Etho Vision XT software (Nodule, the Netherlands). Each rat was only tested once. The arena was thoroughly cleaned with $75 \%$ ethanol between rats during test.

\section{Elevated plus maze (EMP)}

EMP is an effective tool to evaluate the anxiety on rodents [40]. The elevated plus maze was constructed in the end of training day as previously described [41], with two open arms $(30 \times 5 \times 15 \mathrm{~cm})$ and two closed arms $(30 \times 5 \times 15 \mathrm{~cm})$ that extended from a central, open square $(5 \times 5 \mathrm{~cm})$. The maze was elevated on a pedestal to a height of $45 \mathrm{~cm}$ above the floor. Three measures were tested: the amount of time to explore the open arms relative to the total amount of time to explore the open and closed arms of the maze, recorded as the ratio of time spent in the open arms/time in the arms; and the total number of entries into the open arms relative to the total entries, recorded as the ratio of number of open arms entries/total entries; the time spent in central area. Each rat was tested for $3 \mathrm{~min}$. Measures were assessed using EthoVision XT software (Nodule, the Netherlands). Rat was tested individually once. The maze was thoroughly cleaned with $75 \%$ ethanol between rats during test.

\section{Statistical analysis}

The data are expressed as the mean \pm standard error of the mean. All data were initially tested for normality and

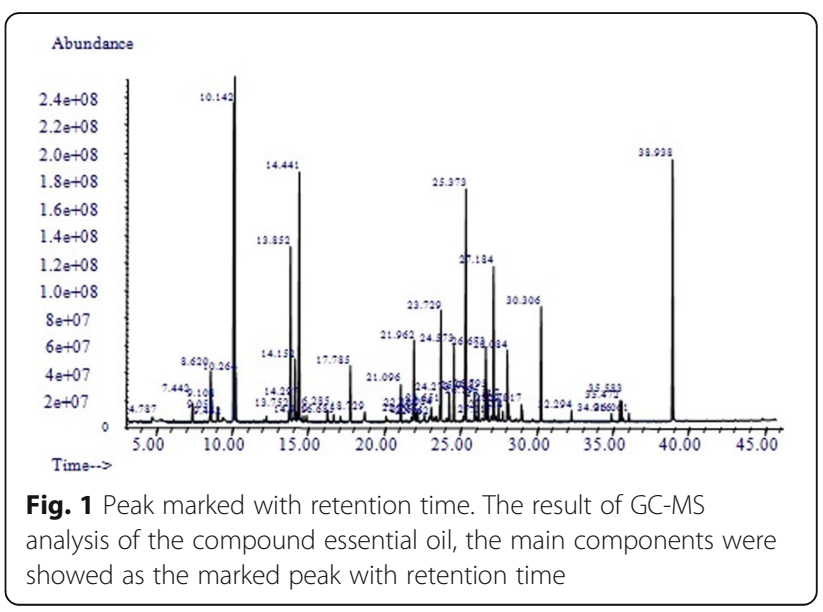


Table 1 Identified components of the compound essential oil

\begin{tabular}{|c|c|c|c|c|c|}
\hline No. & Retention time (min) & Relative Content (\%) & Compound & Molecular weight & Similarity (\%) \\
\hline 1 & 4.787 & 0.55 & hexamethyl cyclotrisiloxane & 222.056 & 95 \\
\hline 2 & 7.442 & 0.86 & (1S)-2,6,6-trimethylbicyclo[3.1.1]hept-2-ene & 136.125 & 97 \\
\hline 3 & 8.62 & 2.31 & (1S)-6,6-dimethyl-2-methylene-bicyclo[3.1.1] heptane & 136.125 & 97 \\
\hline 4 & 9.053 & 0.30 & $(-)$ & & \\
\hline 5 & 9.108 & 0.38 & $(-)$ & & \\
\hline 6 & 9.442 & 0.27 & $(-)$ & & \\
\hline 7 & 10.142 & 15.46 & Tricyclo[5.3.0.0(3,9)]decane & 136.125 & 90 \\
\hline 8 & 10.264 & 0.78 & eucalyptol & 154.136 & 98 \\
\hline 9 & 13.752 & 0.40 & trans-5-methyl-2-(1-methylethyl)- cyclohexanone & 154.136 & 98 \\
\hline 10 & 13.852 & 5.72 & cis-5-methyl-2-(1-methylethyl)-cyclohexanone & 154.136 & 93 \\
\hline 11 & 14.152 & 3.04 & I-menthone & 154.136 & 96 \\
\hline 12 & 14.297 & 0.39 & (1a,23,5a)-5-methyl-2-(1-methylethyl)-cyclohexanol & 156.151 & 91 \\
\hline 13 & 14.441 & 10.31 & 2,6-dimethyl-2,6-octadiene & 138.141 & 90 \\
\hline 14 & 14.919 & 0.27 & alpha-terpineol & 154.136 & 93 \\
\hline 15 & 16.285 & 0.47 & pulegone & 152.12 & 98 \\
\hline 16 & 16.685 & 0.27 & 3-methyl-6-(1-methylethyl)-2-cyclohexen-1-one & 152.12 & 95 \\
\hline 17 & 17.785 & 1.67 & menthyl acetate & 198.162 & 91 \\
\hline 18 & 18.729 & 0.48 & dodecamethyl-cyclohexasiloxane & 444.113 & 90 \\
\hline 19 & 21.096 & 1.22 & caryophyllene & 204.188 & 99 \\
\hline 20 & 21.962 & 3.25 & $(-)$ & & \\
\hline 21 & 22.107 & 0.32 & $\begin{array}{l}\text { (1S-exo)-2-methyl-3-methylene-2-(4-methyl-3- } \\
\text { pentenyl)- bicyclo[2.2.1] heptane }\end{array}$ & 204.188 & 90 \\
\hline 22 & 22.207 & 0.38 & ethyl-3-phenyl-2-propenoic acid ester & 176.084 & 98 \\
\hline 23 & 22.651 & 0.25 & 1-(1,5-dimethyl-4-hexenyl)-4-methyl-benzene & 202.172 & 98 \\
\hline 24 & 22.962 & 0.25 & di-epi-a-cedrene & 204.188 & 96 \\
\hline 25 & 23.084 & 0.66 & tetradecamethyl-cycloheptasiloxane & 518.132 & 91 \\
\hline 26 & 23.651 & 0.51 & $\begin{array}{l}\text { (1S-cis)-1,2,3,5,6,8a-hexahydro-4,7-dimethyl-1- } \\
\text { (1-methylethyl)-naphthalene, }\end{array}$ & 204.188 & 97 \\
\hline 27 & 23.729 & 3.63 & $(-)$ & & \\
\hline 28 & 24.273 & 0.85 & $\begin{array}{l}{[1 \mathrm{R}-(1 \mathrm{a}, 3 \mathrm{3a}, 4 \beta)]-4-\text {-ethenyl-4-trimethyl-3- }} \\
\text { (1-methylethenyl)-cyclohexanemethanol }\end{array}$ & 222.198 & 91 \\
\hline 29 & 24.573 & 2.32 & nerolidol & 222.198 & 91 \\
\hline 30 & 25.373 & 10.19 & $(-)$ & & \\
\hline 31 & 25.928 & 0.98 & 8-epi-ү-eudesmol & 222.198 & 95 \\
\hline 32 & 26.195 & 0.84 & gama.-eudesmol & 222.198 & 99 \\
\hline 33 & 26.673 & 3.66 & $(-)$ & & \\
\hline 34 & 26.795 & 0.91 & 7-epi-a-selinene & 204.188 & 95 \\
\hline 35 & 27.017 & 0.37 & $(-)$ & & \\
\hline 36 & 27.184 & 5.14 & $(-)$ & & \\
\hline 37 & 27.517 & 0.69 & Z-a-trans-bergamotol, & 220.183 & 91 \\
\hline 38 & 27.784 & 0.33 & E-cis,epi-a-santalol, & 220.183 & 97 \\
\hline 39 & 28.084 & 2.38 & $(-)$ & & \\
\hline 40 & 28.173 & 0.52 & methyl tetradecanoate & 242.225 & 99 \\
\hline 41 & 29.017 & 0.89 & Cis-lanceol & 220.183 & 90 \\
\hline 42 & 30.306 & 3.66 & isopropyl myristate & 270.256 & 95 \\
\hline
\end{tabular}


Table 1 Identified components of the compound essential oil (Continued)

\begin{tabular}{llllll}
\hline No. & Retention time (min) & Relative Content (\%) & Compound & Molecular weight & Similarity (\%) \\
\hline 43 & 32.294 & 0.33 & methyl hexadecanoic acid ester & 270.256 & 99 \\
44 & 34.916 & 0.26 & 13-hexyloxacyclotridec-10-en-2-one & 280.24 & 93 \\
45 & 35.472 & 0.64 & (E,E)- methyl-9,12-octadecadienoic acid ester & 294.256 & 99 \\
46 & 35.583 & 0.66 & Methyl-11-octadecenoic acid ester & 296.272 & 99 \\
47 & 36.061 & 0.27 & methyl stearate & 298.287 & 99 \\
48 & 38.938 & 9.70 & [R-(Z)]-12-hydroxy-, methyl-9-octadecenoic & 312.266 & 94 \\
& & acid ester & &
\end{tabular}

(-) not identified

homogeneity of variance and then analyzed using one-way analysis of variance (ANOVA) or a Kruskal-Wallis test. In addition, the least significant difference (LSD) or Mann-Whitney test was adopted for group comparisons. The statistics of ANOVA and Kruskal-Wallis tests were represented as $\mathrm{F}$ and $\mathrm{H}$ respectively. All data were analyzed with Statistical Package for the Social Sciences (SPSS) software, version 17.0 (SPSS, Chicago, IL, USA). $P$ values $<0.05$ were considered statistically significant.

\section{Results}

\section{GC-MS analysis}

The approximate relative amounts of individual components were expressed as peak area relative to the total peak area. The peak marked with retention time was shown in Fig. 1, and the components were shown in Table 1.

According to the analysis of GC-MS, there are 48 components in the compound essential oil, 38 of them has been identified. The highest relative content is Tricyclo[5.3.0.0 $(3,9)]$ decane, with a proportion of $15.46 \%$, followed by 2,6-dimethyl-2,6-octadiene(10.31\%) and [R-(Z)]-12-hydroxy-, methyl-9-octadecenoic acid ester(9.7\%).

\section{Bodyweight}

There was a significant difference among the three groups in daily bodyweight $[\mathrm{F}(2,63)=10.304, p=0.000]$. The bodyweight of CSD group showed a significant decrease compared with CON group $(p=0.000)$. However, there was no significant difference seen between CSD and CEO group in the LSD test $(p=0.482)$. Similarly, the growing trend of CON group was obviously higher than the other two groups during the experimental days (Fig. 2).

\section{Access of WST}

The result of WST was significantly different $[\mathrm{F}(2,30)=$ $33.738, P=0.000]$. CSD evidently cut down the swimming endurance time compared with CON group ( $p=$ 0.000 ), and CEO extended the swimming time significantly ( $p=0.000)$ in LSD test (Fig. 3).

\section{Access of OFT}

The analysis of parameters in OFT was showed in Fig. 4. The time spent in central area result in significant difference among the groups in Kruskal-Wallis test $[H(2)=19.531, p=0.000]$; in the Mann-Whitney test, the central time in CSD group exhibited a evident increase compared with the CON group $(p=0.000)$, and CEO decreased the one compared with CSD group $(p=0.028)$. The parameters of horizontal activity showed a consistent result that the CSD rats enhanced these parameters significantly while $\mathrm{CEO}$ decreased them without significant difference, including total distance travelled $[\mathrm{H}(2)=21.392$, $p=0.000$; CON vs CSD: $p=0.000$; CSD vs CEO: $P=$ $0.768]$, number of crossing squares $[\mathrm{H}(2)=21.666, p=$ 0.000; CON vs CSD: $p=0.000$; CSD vs CEO: $P=0.412]$, maximum continuous distance travelled $[\mathrm{H}(2)=21.383$, $p=0.000$; $\mathrm{CON}$ vs CSD: $p=0.000$; CSD vs CEO: $P=$ $0.869]$, and mean velocity $[\mathrm{F}(2,30)=23.755, p=0.000$; $\mathrm{CON}$ vs CSD: $p=0.000$; CSD vs CEO: $P=0.726]$. On the other hand, vertical activity was detected as number $[\mathrm{H}(2)=21.608, p=0.000 ; \mathrm{CON}$ vs CSD: $p=0.000$; CSD vs CEO: $P=0.054]$ and time $[\mathrm{H}(2)=12.731, p=0.002$; $\mathrm{CON}$ vs CSD: $p=0.001$; CSD vs CEO: $P=0.017$ ] of standing on hind feet of rats, the CSD enhanced both number and time of vertical activity, while CEO reduced them. There was no significant difference in the number of grooming behavior $[\mathrm{H}(2)=5.864, p=0.053]$, and the time of grooming resulted in significant difference $[\mathrm{H}(2)=9.729, p=0.008$; $\mathrm{CON}$ vs CSD: $p=0.027$; CSD vs CEO: $P=0.716]$, no significant difference was found between CSD and CEO groups in grooming behavior. Number the defecations resulted in significant difference $[\mathrm{H}(2)=7.669, p=0.022]$, the defecations of CSD group increased significantly compared with the CON group $(p=0.019)$, and CEO decreased the number compared the CSD group $(p=0.032)$.

\section{Access of EPM}

The ratio of entries in the open arms changed significantly among the three groups $[\mathrm{F}(2,30)=5.728, P=0.008]$. Compared the CSD group, the rats in $\operatorname{CON}(p=0.012)$ and CEO $(p=0.004)$ groups visibly visited the open arms more frequently. However, the other measure that explain the 

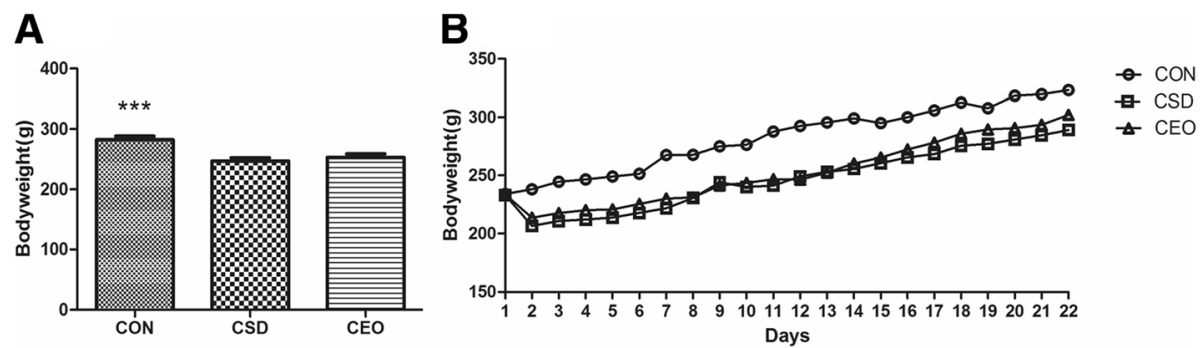

Fig. 2 Bodyweight. All data were represented as the mean \pm SEM $(n=11)$, ${ }^{* * *}$ refers to $p<0.001$ vs CSD group. The bodyweight of CON rats increased significantly compared with the CSD rats (a). Details of daily body weight changes, as recorded at 9:00 during training days (b). The growth of bodyweight of CON group exhibited a higher growing trend

open arm visiting which recorded as the ratio of time in open arms resulted in no significant difference changes $[\mathrm{H}(2)=1.589, p=0.045]$, also the trend of changing was similar to the former measure. Time spent in the central area, which reflects the decision making ability, showed a significant difference $[\mathrm{H}(2)=9.419, p=0.009]$. Although the central time in CSD group decreased without significance $(p=0.224)$, the index of CEO group increased significantly compared with the CSD group ( $p=0.001)$ (Fig. 5).

\section{Discussion}

Aerial diffusion is a fast way for aromatic therapy to bring into effect since it takes only $4 \mathrm{~s}$ to induce the response of central nervous system [42]. It takes advantage of respiration administration which begins with the absorption of volatile molecules through the nasal mucosa [43], meanwhile, the volatile molecules get into the lung followed by gas exchanging, then reach circulation system. Odor molecules are transformed into chemical signals, which could stimulate the releasing of neurotransmitters in brain, then balance the nerve system [44]. This mode of operation can effectively influence the functional brain changes, especially mental disorder and mood. Central fatigue is a

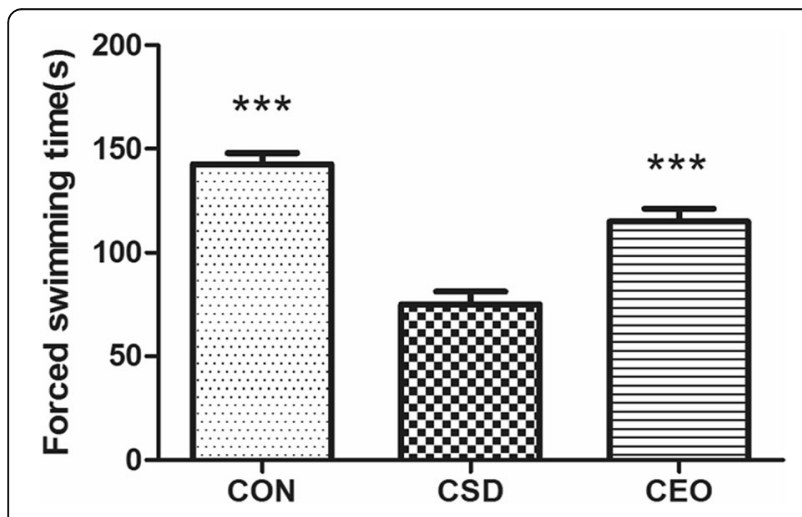

Fig. 3 Swimming time of weight loaded forced swimming test. All data were represented as the mean $\pm \operatorname{SEM}(n=11)$, ${ }^{* *}$ refers to $p<0.001$ vs CSD group. The swimming time of CON group was significantly longer compared with CSD group, CEO increased the swimming time significantly compared with the CSD group common condition revolving cognitive dysfunction, negative emotion, and physical weakness. Our study indicated that the inhalation of compound essential oil can directly attenuate negative behavioral changes after central fatigue on rats.

It has been proved that Citrus limonum [45], Citrus paradise [46], Citrus aurantium [47], Mentha piperata [48], Santalum album [49] have the beneficial effects on stress, anxiety, depression, oxidant [50], oxidant stress, and also could modulate sympathetic activity. Meanwhile, Styrax benzoin [51], Rhodiolae crenulatae radix et rhizoma [52], Camellia sinensis (linn.)o. ktze [53] and Acori tatarinowii rhizoma [54] all have been studied to anti-fatigue effectively by regulating energy process, reducing metabolism products, improve the function of Brain Blood Barrier. Since no evidence has been found that the compounds of these gradients could ameliorating central fatigue, this study proved that the compound essential oil inhalation was effective.

According to the result of GC-MS analysis, there are 5 main groups of material, esters, alcohols, terpenes, alkanes, and alkenes. The eaters and alcohols could inspire the central nervous system [33], while the terpenes provide the anti-oxidative effect [55]. Among these identified components, Tricyclo[5.3.0.0(3,9)] decane is the highest relative content component in the compound essential oil, in addition, 2,6-dimethyl-2,6-octadiene, and [R-(Z)]-12-hydroxy-, methyl-9-octadecenoic acid ester also have much higher proportion than other identified components. However, the compound essential oil alleviated central fatigue as a whole formula, it is difficult to conclude that the highest contents are the active ingredients in the compound essential oil. The deeper mechanism of these chemical substance on central fatigue remains further study.

The CEO group showed increased physical function. It is studied that central fatigue has a strong negative impact on the physical performance [16]. The WFS test reflects the entire fatigue state especially physical endurance by the swimming time. The swimming time of CSD rats decreased evidently, which exhibited a weakness of body 

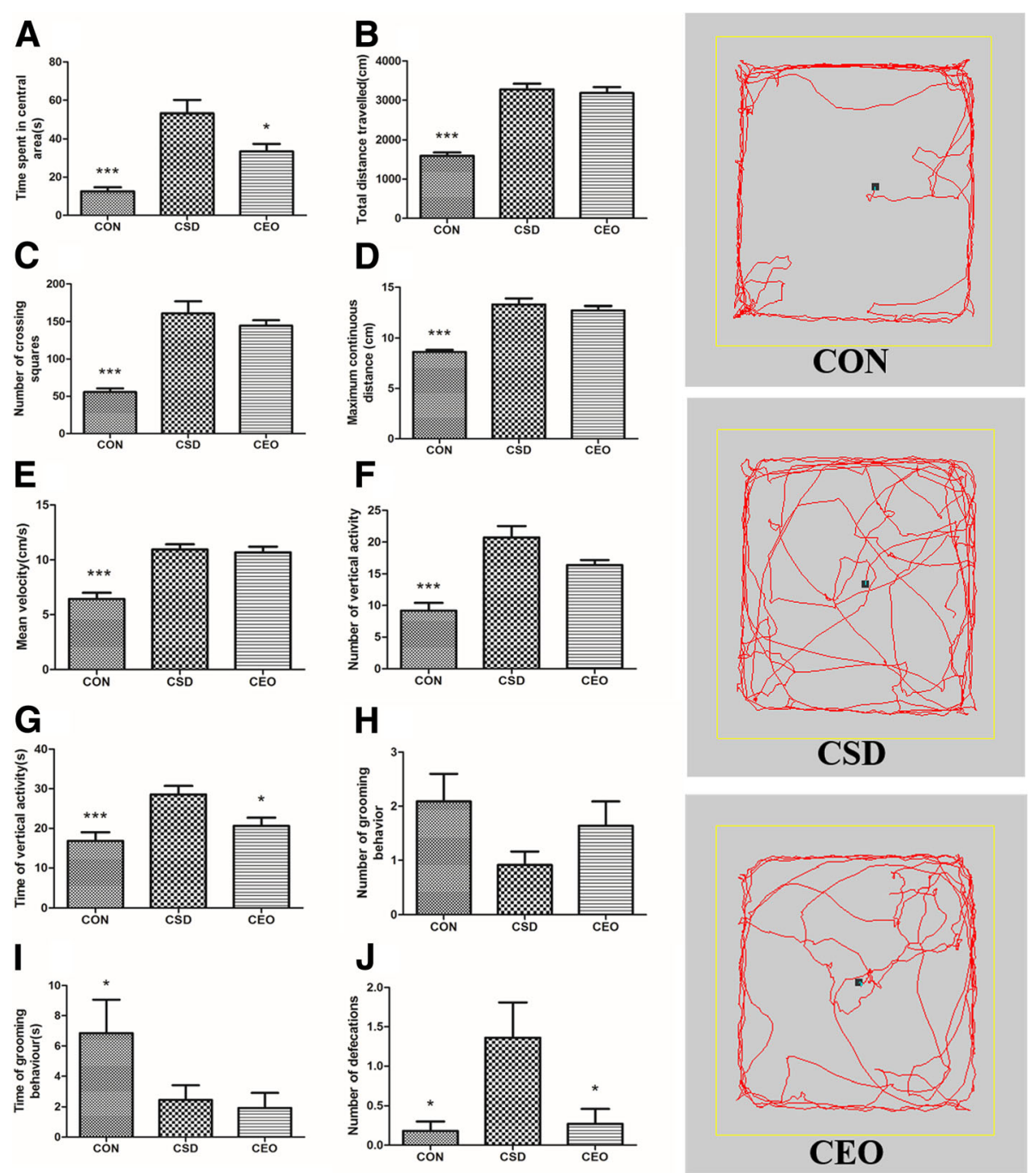

Fig. 4 Assessment of open field test. All indexes were recorded in a test of $5 \mathrm{~min}$. All data were represented as the mean \pm SEM $(n=11)$, * refers to $p<0.05$, ${ }^{* *}$ refers to $p<0.000$ vs. CSD group. The time spent in center of CON group was significantly shorter compared with CSD group, and CEO decreased the central time (a). The total distance travelled (b), number of crossing squares (c), max continuous distance (d), mean velocity (e) of CON group all decreased significantly compared with CSD group respectively, and treatment of CEO showed a reduction trend on these parameters. Number and time recorded of vertical activity $(\mathbf{f}, \mathbf{g})$ showed the same situation as horizontal activity. No significant difference was found in the number of grooming behavior (h). The time of grooming (i) in CON group were significantly higher than CSD group. Number of defecations (j) of CSD group increased significantly compared with CON group, and CEO was seen to decrease the measure significantly

function. Compared with the non-treated CSD rats, rats in CEO group showed a longer endurance during the WFS test, suggested that the inhalation of compound essential oil could improve the physical function. The body weight could be affected by two reasons: the food intake and the energy consumption. Since central fatigue is closely related to emotion, the appetite is supposed to be affected and result in lower food intake. Bodyweight can reflect the motivation in food intake, and the energy consumption and metabolism as well during central fatigue. However, the bodyweight was showed on significant change after inhalation treatment.
The compound essential oil improved behavioral performance associated with anxiety and cognitive function. The Open field test is widely used in emotion evaluation on rodents, especially, anxiety. Thigmotaxis (preference for peripheral over central parts of the open field) was recorded as time spent in the central arena [56]. Evidently increasing central time reflects a lower capacity in space cognition because normal rats would realize the environment then rapidly leave from the novel and open filed center space [57]. Given that the CSD increased central time, there was an evident decrease after compound essential oil treatment that indicating the enhancement of 

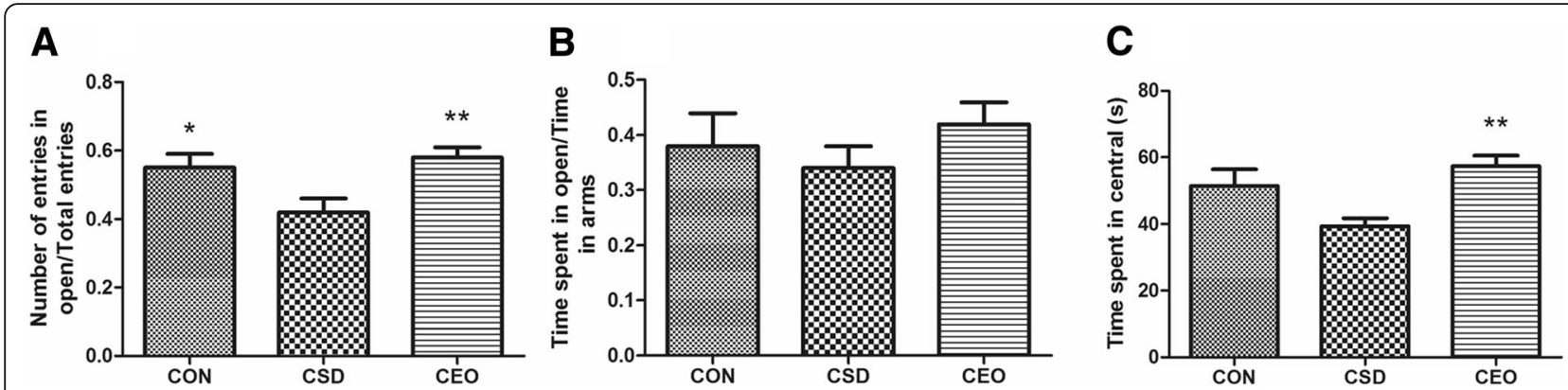

Fig. 5 Assessment of elevated plus maze. All data were represented as the mean \pm SEM $(n=11)$, * refers to $p<0.05{ }^{* *}$ refers to $p<0.01$ vs. CSD group. The ratio of number of entries in the open /total entries (a) in CSD group decreased significantly compared with CON group. CEO increased the ratio. There was no significant difference in the ratio of time spent in open/total arms (b), whereas the trend showed same as before. The reduction of central time (c) in CSD was not significant, however the treatment CEO increased the measure compared with CSD group

space cognize capacity. Consist with our previous research [37], the increasing central time represented a high-stress state and anxiolytic-like behavior of rodent, which has also been relieved by CEO. Locomotor activity was composed by horizontal activity and vertical activity. It has been reported that physical fatigue could decrease locomotor activity [58], unfortunately, few literature reported the changes in locomotor activity during central fatigue. The measures of horizontal activity in this study composing total distance travelled, number of crossing squares, maximum distance travelled, and the mean velocity, it is showed a significant increase in CSD rats, and a decreasing trend after inhalation treatment without statistical significance. We hypothesized this result can reflect a high-stress state in CSD rats, accompanying by fear and irritability, and the relaxing property of compound essential oil attenuated these behavioral changings. Similarly, the two parameters of vertical activity in CSD, namely the number and total time of vertical activity, exhibited an evident enhancement, which were decreased in CEO group, implying the antianxiety action of inhalation treatment. Grooming behavior and defecation also reflect anxiety, in this study, a reduction of grooming was seen in CSD group, and CEO improved the grooming occurrence without significance. Although there was a slight, non-significant decrease in CEO group of grooming time, we consider this could be ignored. An evident increase of defecation number was observed in CSD group during the test, meanwhile an obvious decrease was showed in CEO group, both suggesting an improvement of essential oil in stress, fear and anxiety.

Elevated plus maze is a classic paradigm in anxiety evaluation. The ratio of entries number in open of CSD group went through a decrease, and CEO rats visited the open arms more frequently. The same trend was seen in the other measure, ratio of time in open arm, but without significance. Thus it could demonstrate a property of compound essential oil in anti-anxiety during central fatigue. In addition, this test not only assessed factors related to anxiety, but also evaluates the subjects' risk assessment and decision-making ability by measuring the time spent in the center. It has been found that less time spent in central represents a weakness of this ability [59]. Although the central time of CSD group decreased without significance, there was an evident increase in CEO group, which implies a clue in effect of high level brain cognitive function in our essential formula.

\section{Conclusion}

The compound essential oil could attenuate central fatigue on rats by enhancing physical endurance, reducing negative emotion as decreasing depression and anxiety-like behavior, and improving space cognition and decision-making ability.

\section{Abbreviations}

CEO: Compound essential oil group; CON: Control group; CSD: Chronic sleep deprivation group; EPM: Elevated plus maze; OFT: Open field test;

WFS: Weight-loaded forced swimming

\section{Acknowledgements}

We wish to thank Dr. Xiumei Wu and Prof. Huai Xiao from Institute of Entomoceutical Research, Dali University, for their work on GC-MS analysis.

\section{Funding}

This work was supported by the Natural Science Foundation of Beijing Municipality (Beijing Natural Science Foundation)(No.7162124), which supported design, analysis, and the interpretation of data in this study, and the Collaborative Innovation Project of the Beijing University of Chinese Medicine (No.522/0100604299), and the XinAo Awarding Foundation of the Beijing University of Chinese Medicine (No.1000062720044/006), which both provided the animals, medicine, and other materials needed in the study.

\section{Availability of data and materials}

All data and materials are available and could be obtained from the corresponding author FL.

\section{Authors' contributions}

Designed the experiments, analyzed the data, and wrote the first draft of the manuscript: $\mathrm{CH}$. Conceived the research hypotheses and ideas, drafted the manuscript: FL. Conducted the drug preparation, essential oil preparation, related data analyze: ST. Conducted the 21-day animal model and essential oil inhalation, and daily bodyweight recording, related data processing: MM and WZ. Contributed to the behavior tests (weight-loaded forced swimming, 
open filed test, elevated plus maze), related data analysis and interpretation: YL and WYZ. Conducted the gas chromatography-mass spectrometry analysis, related data analysis and interpretation, and discussion on the main conception: HX and XW. All authors have been involved in reviewing and approving the final manuscript.

\section{Ethics approval and consent to participate}

The experiments were approved by the Institutional Animal Ethics Committee of Beijing University of Chinese Medicine. All animals were maintained in accordance with the guidelines outlined by the Chinese legislation on the ethical use and care of laboratory animals. All efforts were made to minimize both animal suffering and the number of animals used to produce reliable data.

\section{Consent for publication}

Not applicable.

\section{Competing interests}

The authors declare that they have no competing interests.

\section{Publisher's Note}

Springer Nature remains neutral with regard to jurisdictional claims in published maps and institutional affiliations.

\section{Author details}

${ }^{1}$ Basic Medicine School, Beijing University of Chinese Medicine, Beijing, People's Republic of China. ${ }^{2}$ Chinese Medicine School, Beijing University of Chinese Medicine, Beijing, People's Republic of China. ${ }^{3}$ Insect Biological Medicine Research Institution, Dali University, Dali, Yunnan, People's Republic of China.

\section{Received: 13 August 2017 Accepted: 13 November 2018}

\section{Published online: 26 November 2018}

\section{References}

1. Smith A. The Olfactory Process and its Effect on Human Behavior. Biology 202 Second Web Reports On Serendip. 1999.

2. Gattefosse RM. Gattefosse's Aromatherapy. In: Essex. England: CW Daniel: 1993.

3. Yim W, Ng AK, Tsang HW, Leung AY. A review on the effects of aromatherapy for patients with depressive symptoms. J Altern Complement Med. 2009;15(2): 187-95.

4. Chnaubelt K. Medical Aromatherapy: Healing With Essential Oils. Berkeley: Frog Ltd; 1999.

5. Shiina $Y$, Funabashi N, Lee K, Toyoda T, Sekine T, Honjo S, Hasegawa R, Kawata T, Wakatsuki Y, Hayashi S, Murakami S, Koike K, Daimon M, Komuro I. Relaxation effects of lavender aromatherapy improve coronary flow velocity reserve in healthy men evaluated by transthoracic Doppler echocardiography. Int J Cardiol. 2008;129(2):193-7.

6. Watt M, Essential oils. Their lack of skin absorption but effectiveness via inhalation. Aromatic Thymes. 1995;3(2):11-3.

7. Yamada K, Mimaki Y, Sashida Y. Anticonvulsive effects of inhaling lavender oil vapour. Biol Pharm Bull. 1994;17(2):359-60.

8. Dalsgaard MK, Secher NH. The brain at work: a cerebral metabolic manifestation of central fatigue? J Neurosci Res. 2007;85:3334-9.

9. Chaudhuri A, Behan PO. Fatigue and basal ganglia. J Neurol Sc. 2000;179: 34-42.

10. Chaudhuri A, Behan PO. Fatigue in neurological disorders. Lancet. 2004;363: 978-88.

11. Harrington ME. Neurobiological studies of fatigue. Prog Neurobiol. 2012;99: 93-105

12. Leavitt VM, De Luca J. Central Fatigue: Issues Related to Cognition, Mood and Behavior, and Psychiatric Diagnoses. PM R. 2010;2:332-7.

13. Eric A, Newsholme EB. Branched-Chain Amino Acids and Central Fatigue. Nutr. 2006:136:274-6

14. Felger JC, Miller AH. Cytokine effects on the basal ganglia and dopamine function:the subcortical source of inflammatory malaise. Front Neuroendocrinol. 2012;33(3):315-27.

15. Grim PF. Relaxation therapies and neurosis: a central fatigue interpretation Psychosomatics. 1972;13(6):363-70.
16. Millet $Y$, Aubert D, Favier FB, et al. Effect of acute hypoxia on central fatigue during repeated isometricleg contractions. Scand J Med Sci Sports. 2009;19: 695-702.

17. Perry N, Perry E. Aromatherapy in the management of psychiatric disorders: clinical and neuropharmacological perspectives. CNS Drugs. 2006;20(4):257-80.

18. Boehm K, Büssing A, Ostermann T. Aromatherapy as an adjuvant treatment in Cancer care - a descriptive systematic review. Afr J Tradit Complement Altern Med. 2012;9(4):503-18.

19. Varney E, Buckle J. Effect of inhaled essential oils on mental Exhaustionand moderate burnout: a small pilot study. J Altern Complement Med. 2013; 19(1):69-71.

20. Steflitsch W, Steiner D, Peinhaupt W, Riedler B, Smuc M, Diewald G. Health promotion through prevention of stress and burnout with essential oils for all professionals at the Otto Wagner Spital in Vienna. Forsch Komplementmed. 2015;22(3):185-94.

21. Corner J, Cawler N, Hildebrand S. An evaluation of the use of massage and essential oils on the wellbeing of cancer patients. Int J Palliat Nurs. 1995; 1(2):67-73.

22. Wilcock A, Manderson C, Weller R, Walker G, Carr D, Carey AM, Broadhurst D, Mew J, Ernst E. Does aromatherapy massage benefit patients with cancer attending a specialist palliative care day Centre? Palliat Med. 2004:18(4):287-90.

23. Graham PH, Browne L, Cox H, Graham J. Inhalation aromatherapy during radiotherapy: results of a placebo-controlled double-blind randomized trial. J Clin Oncol. 2003;21(12):2372-6.

24. Maddocks-Jennings W, Wilkinson JM, Cavanagh HM, Shillington D. Evaluating the effects of the essential oils Leptospermum scoparium (manuka) and Kunzea ericoides (kanuka) on radiotherapy induced mucositis: a randomized, placebo controlled feasibility study. Eur J Oncol Nurs. 2009: 13(2):87-93.

25. Yamashita M, Yamamoto T. Establishment of a rat model of central fatigue induced by chronic sleep disorder and excessive brain tryptophan. Japan J Cogn Neurosci. 2013;15:67-74.

26. Lillehei AS, Halcón LL, Savik K, Reis R. Effect of inhaled lavender and sleep hygiene on self-reported sleep issues: a randomized controlled trial. J Altern Complement Med. 2015;21(7):430-8.

27. Yamashita M, Yamamoto T. Tryptophan and Kynurenic Acid May Produce an Amplified Effect in Central Fatigue Induced by Chronic Sleep Disorder. Int J Tryptophan Res. 2014;7:9-14.

28. Komiya M, Takeuchi T, Harada E. Lemon oil vapor causes an anti-stresseffect via modulating the 5-HT and DA activities in mice. Behav Brain Res. 2006; 172:240-9.

29. Umezu T. Evidence for dopamine involvement in ambulation promotedby pulegone in mice. Pharmacol Biochem Behav. 2010;94:497-502.

30. Lehrner J, Marwinski G, Lehr S. Et Cl. Ambient odors oforange and lavender reduce anxiety and improve mood in a dental office. Physiol Behav. 2005; 86:92-5.

31. Luosheng H, Yanfei GU, Hong LI. Advances in herbal volatile oil and aromatic herbs. China J Chinese Material Medica. 2009;34(12):1605-10

32. National Pharmacopoeia Committee. Pharmacopoeia of People's Republic of China. Beijing: China Medical Science Press; 2015.

33. Wu Y, Zhang Y, Xie G, et al. The Metabolic Responses to Aerial Diffusion of Essential Oils. Plos One. 2012;7(9):e44830.

34. Alhaider IA, Aleisa AM, Tran TT, Alkadhi KA. Sleep depriva-tion prevents stimulation-induced increases of levels of P-CREBand BDNF: protection by caffeine. Mol Cell Neurosci. 2011:46:742-51.

35. Grahnstedt S, Ursin R. Platform sleep deprivation affects deep slow wave sleep in addition to REM sleep. Behav Brain Res. 1985;18:233-9.

36. Han C, Li F, Ma J, Liu Y, Li W, et al. Distinct behavioral and brain changes after different durations of the modified multiple platform method on rats: an animal model of central fatigue. PLOS ONE. 2017;12(5):e0176850. https:// doi.org/10.1371/journal.pone.0176850.

37. Porsolt RD, Bertin A, Jalfre M. Behavioral despair in mice: a primary screening test for antidepressants. Arch Int Pharmacodyn Ther. 1977;229:327-36.

38. Prut $L$, Belzung $C$. The open field as a paradigm to measure the effects of drugs on anxiety-like behaviors: a review. Eur J Pharmacol. 2003;463:3-33.

39. Silva AP, Cerqueira GS, Nunes LC, de Freitas RM. Efects of an aqueous extract of Orbignya phalerata Mart onlocomotor activity and motor coordination in mice and as antioxidant in vitro. Pharmazie. 2012;67(3):260-3.

40. Pellow S, Chopin P, File SE, et al. Validation of open: closed arm entries in an elevated plus-maze as a measure of anxiety in the rat. J neurosci Methods. 1985;14:149-67. 
41. Lister RG. The use of a plus-maze to measure anxiety in the mouse. Psychovharmacolozv. 1987;92:180-5.

42. JuYudong $Y$, Lishanshan, et al. The beneficial effect and application of aromatic plant. Modern Agric Sci. 2015;1:125-7.

43. Lis-Balchin M. Essential. Oils and 'aromatherapy': their modern role in healing. J R Soc Health. 1997;117:324-9.

44. Mori K, Nagao H, Yoshihara Y. The olfactory bulb: coding and processing of odor molecule information. Science. 1999;286(22):711.

45. Komiya M, Takeuchi T, Harada E. Lemon oil vapor causes an anti-stress effect via modulating the 5-HT and DA activities in mice. Behav Brain Res. 2006:172(2):240-9.

46. Haze S, Sakai K, Gozu Y. Effects of fragrance inhalation on sympathetic activity in normal adults. Jpn J Pharmacol. 2002:90(3):247-53.

47. Pultrini Ade M, Galindo LA, Costa M. Effects of the essential oil from Citrus aurantium L. in experimental anxiety models in mice. Life Sci. 2006;78(15): $1720-5$.

48. White PA. Modulatory effects of Mentha piperata on lung tumor incidence, genotoxicity, and oxidative stress in benzo [a]pyrene-treated Swiss albino mice. Environ Mol Mutagen. 2007;48(6):503.

49. Setzer WN. Essential oils and anxiolytic aromatherapy. Nat Prod Commun. 2009:4(9):1305-16.

50. Misharina TA, Samusenko AL. Antioxidant properties of essential oils from lemon, grapefruit, coriander, clove, and their mixtures. Prikl Biokhim Mikrobiol. 2008;44(4):482-6.

51. Ping H, Houlin X, Fang J, et al. Effect of Benzoinum and Borneo Camphor in different proportion on the miceof cerebral ischemia,anoxia and bloodbrain barrier. Pharmacology Clinics Chinese Materia Medica. 2013;29(5):75-8.

52. Abidov M, Crendal F, Grachev S. Et cl. Effect of extracts from Rhodiola rosea and Rhodiola crenulata (Crassulaceae) roots on ATP content in mitochondria of skeletal muscles. Bull Exp Biol Med. 2003;136(6):585-7.

53. Gramza-Michałowska A. Caffeine in tea Camellia sinensis--content, absorption, benefits and risks of consumption. J Nutr Health Aging. 2014; 18(2):143-9.

54. Zhu M, Zhu H, Tan N. Et Cl. The effects of Acorus tatarinowii Schott on 5-HT concentrations, TPH2 and 5-HT1B expression in the dorsal raphe of exercised rats. J Ethnopharmacol. 2014;2(158):431-6.

55. Vaio CD, Graziani G, Gaspari A, et al. Essential oils content and antioxidant properties of peel ethanol extract in 18 lemon cultivars. Sci Hortic. 2010; 126(1):50-5.

56. Mc Devitt RA, Hiroi R, Mackenzie SM, Robin NC, et al. Serotonin 1B autoreceptors originating in the caudal dorsal raphenucleus reduce expression of fear and depression-like behavior. Biol.Psychiatry. 2011;69:780-7.

57. Treit D, Fundytus M. Thigmotaxisas a test for anxiolytic activity in rats. Pharmacol Biochem Behav. 1989:31(4):959-62.

58. Chen W-Z, Liu S, Chen F-F, et al. Prevention of postoperative fatigue syndrome in rat model by Ginsenoside Rb1 via Down-regulation of inflammation along the NMDA receptor pathway in the hippocampus. Biol Pharm Bull. 2015:38:239-47.

59. Rodgers R, Johnson N. Factor analysis of spatiotemporal and ethological measures in the murine elevated plus-maze test of anxiety. Pharmacol Biochem Behav. 1995;52:297-303.

Ready to submit your research? Choose BMC and benefit from:

- fast, convenient online submission

- thorough peer review by experienced researchers in your field

- rapid publication on acceptance

- support for research data, including large and complex data types

- gold Open Access which fosters wider collaboration and increased citations

- maximum visibility for your research: over $100 \mathrm{M}$ website views per year

At BMC, research is always in progress.

Learn more biomedcentral.com/submissions 